\title{
Histoplasmosis diseminada. Una infección oportunista en pacientes con infección por VIH. Experiencia en el Hospital Nacional Prof. A. Posadas, 2011-2017
}

\author{
Bettina Francini', María Cecilia Cánepa', Carolina Lamonica', Paula Capece², \\ Gladys Posse', Vanesa Sanguineri', Ana Belén Di Sanzo³, Celeste Berton³, \\ Noelia Martinelli3, Oscar Posada ${ }^{3}$, Karen Marsiglia ${ }^{3}$ y Romina Proni Maiolini ${ }^{3}$
}

\section{Disseminated histoplasmosis. An oportunistic infection in HIV positive patients} Experience in the Hospital Nacional Prof. A. Posadas, 2011-2017

Disseminated histoplasmosis is an endemic systemic mycosis, caused by the dimorphic fungus Histoplasma capsulatum. The clinical manifestations depend on the inhaled fungal load, the immunological state of the patient and the virulence of the infecting fungal strain. The disseminated variant is most frequent in immunocompromised patients, with $90 \%$ of cases in patients with positive serology for HIV. In this series, 37 patients with diagnosis of HIV and disseminated histoplasmosis were evaluated. The $43.2 \%$ of the patients did not know their serology prior to the consultation due to histoplasmosis. The main clinical causes were impregnation syndrome (67.6\%), fever $(64.9 \%)$, respiratory symptoms $(62.2 \%)$ and mucocutaneous manifestations $(67.6 \%)$, among others. The $94.6 \%$ of the patients presented anemia, $75.7 \%$ had bicytopenia and $32.4 \%$ pancytopenia. The sensitivity of the blood cultures was $70.4 \%$. The $86.5 \%$ of the patients did not have another opportunistic infection concomitant at the time of diagnosis. In $83.8 \%$ of patients, disseminated histoplasmosis was the first AIDS disease. A mortality of $14.7 \%$ was recorded.

Keywords: Histoplasma capsulatum; HIV; disseminated histoplasmosis.

Palabras clave: Histoplasma capsulatum; VIH; histoplasmosis diseminada.

\section{Introducción}

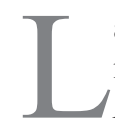

a histoplasmosis diseminada es una micosis sistémica endémica, causada por el hongo dimórfico Histoplasma capsulatum. Es una enfermedad cosmopolita. Se ha estimado que existen mundialmente 40 millones de enfermos y se calculan 200.000 casos nuevos al año ${ }^{1}$.

Las manifestaciones clínicas de la histoplasmosis dependen principalmente de la carga fúngica inhalada, del estado inmunológico del paciente y de la virulencia de la cepa infectante. La presentación de la enfermedad suele tener curso benigno en inmunocompetentes, siendo la forma diseminada una rareza en los mismos. Por el contrario, es la forma más frecuente en inmunosuprimidos, especialmente en aquellos que padecen el virus de la inmunodeficiencia humana $(\mathrm{VIH})^{2}$. El 90\% de los casos se registra en este grupo de pacientes ${ }^{3}$. Es aceptada como enfermedad marcadora de síndrome de la inmunodeficiencia adquirida (SIDA) desde $1987^{4}$. La asociación VIH-histoplasmosis en nuestro país ha sido comunicada con una prevalencia entre 5,3 y $6 \%{ }^{5}$.

El microorganismo crece en suelos húmedos $\mathrm{y}$ en climas templados. La presencia de excrementos de pájaros y murciélagos acelera la esporulación y las corrientes de aire dispersan los conidios distancias importantes. De esta forma, aumenta la exposición a los mismos en poblaciones distantes ${ }^{4}$. Actualmente, la frecuente migración, el turismo y las actividades laborales hacen de esta enfermedad la micosis respiratoria más frecuente del mundo ${ }^{5}$.

Los objetivos del trabajo son describir las principales características epidemiológicas de la población y presentación clínica de pacientes co-infectados con VIH e histoplasmosis diseminada y comparar los datos obtenidos con la literatura médica disponible, determinar otras infecciones oportunistas (IO) concomitantes, antecedentes de enfermedades marcadoras de SIDA, estado inmunológico del hospedero al momento de la infección, sensibilidad de los hemocultivos y mortalidad durante la internación.

\section{Materiales y Métodos}

Se llevó a cabo una búsqueda retrospectiva de todos los casos de pacientes con histoplasmosis diseminada y serología positiva para VIH ingresados en la base de datos
'Medicina Interna, Hospital Nacional Prof. A. Posadas. Buenos Aires, Argentina.

${ }^{2}$ Servicio de Laboratorio, Sector de Micología, Hospital Nacional Prof. A. Posadas. Buenos Aires, Argentina.

${ }^{3}$ Hospital Nacional Prof. A. Posadas. Buenos Aires, Argentina.

Conflictos de interés: Ninguno para declarar.

Financiamiento: Sin financiamiento externo

Recibido: 11 de enero de 2018 Aceptado: 30 de octubre de 2018

Correspondencia a: María Cecilia Cánepa mccanepa@hotmail.com 
del Servicio de Clínica Médica y Servicio de Micología del Hospital Nacional Profesor Alejandro Posadas, Buenos Aires, Argentina, desde el 1 de abril de 2011 hasta el 31 de julio de 2017.

Se realizó un estudio observacional, descriptivo y retrospectivo.

Se recogieron de forma sistemática los datos a partir de la historia clínica de pacientes internados o ambulatorios y los mismos se volcaron en una ficha confeccionada para tal objetivo (Anexo 1).

Se consideraron las siguientes características: sexo, edad, estado inmunológico, manifestaciones clínicas, inicio de la sintomatología, momento de la consulta con el equipo de salud, adherencia al tratamiento antiretroviral (TARV), tipo de muestras donde se aisló $H$. capsulatum, alteraciones de laboratorio, otras infecciones oportunistas al momento de la consulta, antecedentes de otras enfermedades marcadoras de SIDA, tratamiento recibido, mortalidad durante la internación o durante los tres primeros meses luego del diagnóstico en pacientes ambulatorios.

El diagnóstico de histoplasmosis se estableció por la identificación de $H$. capsulatum en muestras clínicas de los pacientes (sangre, piel, mucosas, material respiratorio y biopsias tisulares). Se realizaron exámenes micológicos directos y cultivos. Primeramente, se visualizaron levaduras intracelulares con tinción bipolar en el citoplasma de macrófagos teñidos con coloración de Giemsa. Luego se aisló el hongo mediante el cultivo a $37^{\circ} \mathrm{C}$, en agar infusión cerebro corazón adicionado con cloranfenicol, para obtener su fase levaduriforme y a $28^{\circ} \mathrm{C}$, en agar Sabouraud miel con cloranfenicol y agar Sabouraud Dextrosa con cloranfenicol y cicloheximida, para obtener su fase filamentosa. Posteriormente, se identificó la fase micelial en base a características macro y micromorfológicas de la colonia que, a temperatura ambiente, crece como un micelio filamentoso y su disociación muestra micro y macroconidias.

Se incluyó el recuento de linfocitos T CD4 sólo si se contaba con el dato al momento del diagnóstico de histoplasmosis o los seis meses previos al mismo.

\section{Criterios de inclusión}

- Pacientes mayores de 18 años con infección por VIH con diagnóstico de histoplasmosis diseminada por la identificación de $H$. capsulatum en muestras de sangre, piel, mucosas, material respiratorio y biopsias tisulares.

\section{Criterios de exclusión}

- Pacientes mayores de 18 años, libres de infección por VIH, con diagnóstico de histoplasmosis diseminada.

- Pacientes mayores de 18 años, infectados por VIH, que presenten cuadro compatible sin confirmación micológica.
- Pacientes mayores de 18 años, con patología oncológica, inmunodeficiencia primaria u otra enfermedad, que utilice en su tratamiento inmunosupresores.

Las variables categóricas fueron descritas a través de frecuencias y porcentuales y las cuantitativas con media y desvío estándar (DE) o mediana y rango intercuartil (RIC) según corresponda. Se utilizó para el análisis el programa INFOSTAT.

\section{Resultados}

De los 37 pacientes con diagnóstico de infección por VIH e histoplasmosis diseminada, 67,6\% fueron varones, con una relación hombre/mujer de 2:1. La edad media fue de 41 años (DE 10,4).

El 43,2\% de los pacientes no sabía su serología en forma previa a la consulta por histoplasmosis. La mediana del recuento de LT CD4 fue de 19 céls/uL (RIC 30).

La demora en la consulta arrojó una mediana de 61 días (RIC 59), consultando sólo 11\% antes del mes del inicio de la sintomatología.

Las principales manifestaciones clínicas fueron: síndrome de impregnación: febrícula, pérdida de peso, sudoración nocturna $(67,6 \%)$, fiebre $(64,9 \%)$, síntomas respiratorios $(62,2 \%)$, manifestaciones cutáneas $(45,9 \%)$, manifestaciones mucosas $(32,4 \%)$, manifestaciones muco-cutáneas $(67,5 \%)$ y síntomas digestivos $(29,7 \%)$ (Tabla 1).

Entre las alteraciones de laboratorio se encontró: anemia en $94,6 \%$ de los pacientes, leucopenia en $67,6 \%$, plaquetopenia en $43,2 \%$. El 75,7\% presentó bicitopenia y $32,4 \%$ pancitopenia. Se evidenció aumento de transaminasas en $43,2 \%$ y aumento de fosfatasa alcalina (FAL) en $29,7 \%$. Trece pacientes tenían lactato deshidrogenasa (LDH) elevada $(35,1 \%)$. Se realizó medición de ferritina en $35 \%$ de los pacientes y de éstos $76,9 \%$ presentaban elevación de la misma (Tabla 2).

Tabla 1. Manifestaciones clínicas en pacientes con infección por VIH e histoplasmosis diseminada $(n=37)$

\begin{tabular}{lcc|}
\hline Síntomas o hallazgos & n de casos & $\%$ \\
Síndrome de impregnación & 25 & 67,6 \\
Fiebre & 24 & 64,9 \\
Síntomas respiratorios & 23 & 62,2 \\
Manifestaciones cutáneas & 17 & 45,9 \\
Manifestaciones mucosas & 12 & 32,4 \\
Síntomas digestivos & 11 & 29,7 \\
Otros & 9 & 24,3 \\
\hline
\end{tabular}




\begin{tabular}{lcc|}
$\begin{array}{l}\text { Tabla 2. Alteraciones de laboratorio en pacientes con } \\
\text { infección por VIH e histoplasmosis diseminada }(\mathbf{n}=\mathbf{3 7})\end{array}$ \\
\hline $\begin{array}{l}\text { Alteraciones de } \\
\text { laboratorio }\end{array}$ & $\mathbf{n}$ & $\%$ \\
Anemia & 35 & 94,6 \\
Bicitopenia & 28 & 75,7 \\
Leucopenia & 25 & 67,6 \\
\hline Elevación de transaminasas & 16 & 43,2 \\
\hline Plaquetopenia & 16 & 43,2 \\
\hline Pancitopenia & 12 & 32,4 \\
\hline Elevación de fosfatasa alcalina & 11 & 28,7 \\
\hline
\end{tabular}

Se recuperó $H$. capsulatum de lavado bronquioloalveolar (BAL) en $27 \%$ de los casos, de muestras cutáneas $40,5 \%$ y de muestras mucosas en $24,3 \%$ (12 pacientes). En 75\% (9/12) la lesión se ubicaba en la cavidad oral y la totalidad de las mismas (9/9) se localizó en el paladar. El $25 \%$ restante se recuperó de amígdalas, faringe y laringe (3/12). Además, se recuperó $H$. capsulatum de la escarificación de la mucosa del tabique nasal de un paciente con perforación del mismo en el examen físico. También se aisló en biopsias de intestino delgado y ganglios linfáticos.

Se obtuvo hemocultivos en $73 \%$ de los pacientes; el resultado fue positivo en $70,4 \%$ (19/27).

Se realizó reacción de polimerasa en cadena (RPC) dirigida a una proteína de $100 \mathrm{KDa}$ esencial para la supervivencia del hongo en las células humanas ${ }^{6}$, en siete muestras de lesiones mucosas (mucosa yugal, paladar, tabique nasal, amígdala, laringe e intestino delgado). La misma fue positiva en seis casos. Se realizó en tres muestras de piel y en una muestra respiratoria. En estos casos se obtuvo resultado positivo.

El $86,5 \%$ no tuvo otra IO concomitante al momento del diagnóstico. El 13,5\% que sí la tuvo (5/37) presentó: candidiasis esofágica, criptococosis diseminada, toxoplasmosis cerebral, sarcoma de Kaposi cutáneo, tuberculosis pulmonar, salmonelosis sistémica no tífica y Mycobacterium avium intracellulare (MAI) (Tabla 4). En $83,8 \%$ de los pacientes la histoplasmosis diseminada fue la primera enfermedad marcadora de SIDA (31/37).

De los pacientes que sabían su serología al momento del diagnóstico, 66,6\% no tomaba TARV (14/21) y 33,4\% (7/21) lo hacía en forma irregular.

Un paciente se retiró de la institución luego de recibir el diagnóstico, sin iniciar tratamiento y no se conocen datos de su evolución. Un paciente se trató en forma ambulatoria con itraconazol (1/36) y otro se derivó para realizar tratamiento con anfotericina en otro centro. De este último, se desconoce su evolución posterior. E1 94,4\% de los pacientes (34/36) se internó y realizó tratamiento con anfotericina deoxicolato $1 \mathrm{mg} / \mathrm{kg}$ /día más itraconazol.
Tabla 3. Tipo de muestra a partir de las cuales se realizó el diagnóstico de histoplasmosis diseminada (HD) en pacientes con infección por VIH

\begin{tabular}{lcc}
\hline Tipo de muestra $(\mathbf{n}=\mathbf{3 7})$ & $\mathbf{n}$ & $\%$ \\
Escarificación/biopsia cutánea & 15 & 40,5 \\
Lavado bronquiolo-alveolar & 10 & 27 \\
Escarificación/biopsia de mucosa & 9 & 24,3 \\
Esputo & 3 & 8,1 \\
Biopsia ganglionar & 2 & 5,4 \\
Biopsia de laringe & 1 & 2,7 \\
Biopsia faríngea & 1 & 2,7 \\
Exudado de fauces & 1 & 2,7 \\
Biopsia de intestino & 1 & 2,7 \\
Biopsia de amígdala & 1 & 2,7 \\
Biopsia ganglionar & 1 & 2,7 \\
Biopsia bronquial & 1 & 2,7 \\
\hline
\end{tabular}

Tabla 4. Infecciones oportunistas concomitantes al diagnóstico de histoplasmosis diseminada en $5 / 37(13,5 \%)$ casos con infección por VIH/SIDA

\begin{tabular}{lll}
\hline Infección oportunista & $\mathbf{n}$ & $\%$ \\
Candidiasis esofágica & 2 & 5,4 \\
Criptococosis diseminada & 1 & 2,7 \\
Mycobacterium avium intracellulare & 1 & 2,7 \\
Sarcoma de Kaposi cutáneo & 1 & 2,7 \\
Tuberculosis pulmonar & 1 & 2,7 \\
Toxoplasmosis cerebral & 1 & 2,7 \\
Salmonelosis sistémica no tífica & 1 & 2,7
\end{tabular}

El paciente que se trató en forma ambulatoria evolucionó favorablemente. De los pacientes que se internaron, se registró una mortalidad de 14,7\% (5/34).

\section{Discusión}

La histoplasmosis diseminada en pacientes con infección por VIH es una enfermedad potencialmente mortal y es la segunda micosis sistémica más frecuente en Argentina luego de la criptococosis en estos pacientes?

La inmunidad celular suele controlar la diseminación. Por eso, la infección por VIH constituye el factor de riesgo más importante. Otras causas de inmunosupresión como inmunodeficiencias primarias, malignidad o farmacológicas asociadas al trasplante de órganos o tratamiento de enfermedades autoinmunitarias también permiten un escenario propicio para la diseminación hematógena del hongo $0^{8,9}$.

Kauffman señala que la administración masiva de 
TARV en E.U.A. contribuyó a disminuir sustancialmente la prevalencia de la histoplasmosis diseminada asociada al VIH en ese país ${ }^{8}$. Sin embargo, la micosis constituye una infección oportunista importante en nuestro medio. A pesar de que desde el año 2014 la indicación de TARV es universal, la totalidad de los pacientes estudiados no recibía la medicación o lo hacía en forma irregular. Esto podría estar en relación con las dificultades socioeconómicas de la población estudiada y las fallas en la accesibilidad al sistema de salud, que impacta directamente en el diagnóstico y seguimiento de la infección por VIH.

La histoplasmosis diseminada constituyó la primera enfermedad marcadora de SIDA en $83,8 \%$ de los casos. Nuestro resultado fue mayor en comparación con algunas publicaciones $^{3}$. El 43,2\% desconocía su serología al momento de la consulta, similar a lo informado previamente ${ }^{3}$. Esto muestra indirectamente que un importante porcentaje de la población infectada con VIH en Argentina desconoce su diagnóstico.

Nuestro estudio encontró una mayor frecuencia en hombres que en mujeres. Sin embargo, la diferencia fue menor que los datos publicados por otros investigadores $^{3,10}$. El recuento de LT CD4 se recabó en 94,6\% de los pacientes y fue inferior a 150 céls/uL en la totalidad de los mismos, frecuencia coincidente con la literatura médica ${ }^{4}$. La edad media de presentación fue similar a lo publicado por otras series.

El cuadro clínico de pacientes con histoplasmosis diseminada y VIH suele ser inespecífico. Se ha informado la tríada de fiebre, pérdida de peso y tos en $50 \%$ de los pacientes $^{11,12}$. Las manifestaciones de compromiso gastrointestinal son: dispepsia, náuseas, vómitos y diarrea. Las lesiones cutáneas pueden ser pápulas, placas, pústulas, úlceras, lesiones moluscoides, lesiones necróticas e incluso, eritema nodoso. El compromiso mucocutáneo es más frecuente en América Latina, con series que informan su frecuencia entre 40 y $80 \%{ }^{3,9}$, mientras que en América del Norte la frecuencia es aproximadamente de $10 \%{ }^{7,11-15}$

Debido a que la histoplasmosis diseminada se presenta con síntomas constitucionales como pérdida de peso y fiebre, la tuberculosis diseminada es un diagnóstico diferencial importante ${ }^{16}$. El frecuente compromiso cutáneo de la histoplasmosis en América Latina en comparación con Norteamérica simplifica en cierta forma el diagnóstico ${ }^{15}$. Sin embargo, es posible la co-infección. Por este motivo, se deberían investigar ambos agentes ${ }^{16}$. En nuestro estudio, $13,5 \%$ presentó infecciones oportunistas concomitantes (5/37). Sólo uno de ellos presentó tuberculosis pulmonar. Esto difiere de la literatura internacional que publica entre 8 y $15 \%$ de co-infección ${ }^{8,17}$. Los investigadores creemos que esto podría deberse a que no se recabaron datos acerca del seguimiento posterior de estos pacientes.

Los hallazgos de laboratorio frecuentemente resultan inespecíficos pudiendo encontrarse compromiso hemato- lógico con citopenias. Sólo un paciente no presentó alteración hematológica alguna. En los casos que presentan fosfatasa alcalina (FAL) y enzimas hepáticas elevadas, podría corresponder a compromiso hepático por esta infección. Sin embargo, cabe aclarar que este estudio no diferenció pacientes con hepatitis $\mathrm{C}$ crónica por no contar con el dato en la mayoría de los casos. Esta circunstancia dificulta la relación entre compromiso hepático por $H$. capsulatum y compromiso hepático de cualquier otra etiología.

Histoplasma capsulatum puede afectar áreas inusuales en pacientes con inmunocompromiso profundo. Los sitios más frecuentemente comprometidos son la lengua, la mucosa yugal y el paladar ${ }^{18,19}$. En nuestra serie se aisló el hongo de 12 muestras de mucosas. En los casos en que la lesión se ubicaba en la cavidad oral, la totalidad de las mismas (9/9) se localizó en el paladar. Otra característica importante son los síntomas respiratorios. En nuestra serie se aisló $H$. capsulatum en $86,7 \%$ de los pacientes estudiados por síntomas respiratorios.

Los hemocultivos fueron positivos en $70,4 \%$ de los casos. Este dato es algo menor que el de la literatura científica que informa una sensibilidad de $80 \%$ cuando se recurre a las técnicas de lisis/centrifugación ${ }^{11}$.

El diagnóstico de la histoplasmosis diseminada suele requerir algún tiempo y procedimientos invasivos para la obtención de muestras tisulares. Los estudios serológicos pueden ser realizados rápidamente, pero resultan negativos en $75 \%$ de los pacientes con SIDA ${ }^{11}$. La detección antigénica del hongo en plasma y orina es una herramienta diagnóstica de utilidad y que se puede realizar rápidamente pero no se encuentra disponible en todos los centros $^{2,12}$. La observación microscópica del hongo está limitada por la calidad de la muestra y el entrenamiento del operador. En ocasiones, el hongo no produce los conidios característicos de la fase micelial o presenta morfologías coloniales aberrantes, lo que dificulta, demora o impide su identificación. Los métodos moleculares basados en técnicas de RPC resultan atractivos por obtener resultados rápidos y con alta especificidad. La RPC es una herramienta sencilla y prometedora para el diagnóstico rápido de esta micosis. Sin embargo, tampoco se encuentra actualmente disponible en todos los centros ${ }^{20,21}$. En este trabajo se obtuvieron resultados muy alentadores; sin embargo, debido a la pequeña muestra de pacientes se requerirán futuros estudios para la confirmación.

El tratamiento de elección para pacientes con histoplasmosis diseminada moderadamente grave y grave puede ser anfotericina liposomal $3 \mathrm{mg} / \mathrm{kg} /$ día o anfotericina deoxicolato $0,7-1 \mathrm{mg} / \mathrm{kg} /$ día por una o dos semanas seguida de itraconazol $200 \mathrm{mg}$ cada $12 \mathrm{~h}$ por 12 meses. En los casos de enfermedad leve a moderada podrá realizarse tratamiento con itraconazol $200 \mathrm{mg}$ cada $12 \mathrm{~h}$ por 12 meses $^{4}$. 
Los autores concluimos que la histoplasmosis diseminada es una enfermedad grave en los pacientes con infección por VIH/SIDA. Los síntomas clínicos, hallazgos físicos y datos de laboratorio suelen ser inespecíficos. El aislamiento del microorganismo puede demorar tiempo, ser dificultoso y requerir toma de muestras en forma invasiva. La enfermedad está claramente ligada al estado inmunológico de los pacientes. Por dicho motivo, debería pensarse como diagnóstico diferencial en todo paciente infectado por VIH con síndrome febril prolongado, especialmente si tiene LT CD4 menores a 150 céls/uL, citopenias y/o lesiones mucocutáneas concomitantes de etiología no aclarada. Puede existir la presentación junto a otras enfermedades oportunistas. Resulta de suma importancia la concientización de los equipos de salud y la población en general acerca de la detección temprana del VIH y la adherencia al TARV como medida más útil en la prevención de la morbimortalidad por histoplasmosis diseminada.

Agradecimientos: A la Coordinación de Docencia e Investigación y al Servicio de Laboratorio Sección Biología Molecular del Hospital Nacional Prof. A. Posadas.

\section{Resumen}

La histoplasmosis diseminada es una micosis sistémica endémica, causada por el hongo dimórfico Histoplasma capsulatum. Las manifestaciones clínicas dependen de la carga fúngica inhalada, del estado inmunológico del paciente y de la virulencia de la cepa infectante. La variante diseminada es más frecuente en inmunocomprometidos, registrándose $90 \%$ de los casos en pacientes con serología positiva para VIH. En esta serie se evaluaron 37 pacientes con diagnóstico de infección por VIH e histoplasmosis diseminada. El 43,2\% de los pacientes no sabía su serología en forma previa a la consulta por histoplasmosis. Las principales manifestaciones clínicas fueron síndrome de impregnación $(67,6 \%)$, fiebre $(64,9 \%)$, síntomas respiratorios $(62,2 \%)$ y manifestaciones muco-cutáneas (67,6\%), entre otras. El 94,6\% de los pacientes presentó anemia, 75,7\% tenía bicitopenia y 32,4\% pancitopenia. La sensibilidad de los hemocultivos fue de 70,4\%. El $86,5 \%$ no tuvo otra infección oportunista concomitante al momento del diagnóstico. En $83,8 \%$ de los pacientes la histoplasmosis diseminada fue la primera enfermedad marcadora de SIDA. Se registró una mortalidad de 14,7\%.

\begin{tabular}{|c|c|c|c|c|c|c|c|c|c|c|c|c|}
\hline \multicolumn{13}{|c|}{ Anexo 1. Resultados } \\
\hline Casos & Edad & Sexo & $\begin{array}{l}\text { Serología } \\
\text { (+) de VIH } \\
\text { previa al } \\
\text { diagnóstico } \\
\text { de HD }\end{array}$ & $\begin{array}{c}\text { LT CD4 } \\
\text { (céls/uL) }\end{array}$ & $\begin{array}{c}\text { Retardo } \\
\text { en la } \\
\text { consulta } \\
\text { (días) }\end{array}$ & $\begin{array}{l}\text { Manifestaciones } \\
\text { clínicas }\end{array}$ & Laboratorio & $\begin{array}{l}\text { Tipo de } \\
\text { muestra } \\
\text { positiva }\end{array}$ & $\begin{array}{c}\text { Infección } \\
\text { oportunista } \\
\text { concomitante }\end{array}$ & $\begin{array}{c}\text { Primera } \\
\text { enfermedad } \\
\text { marcadora }\end{array}$ & TARV & $\begin{array}{c}\text { Mortalidad } \\
\text { durante la } \\
\text { internación }\end{array}$ \\
\hline 1 & 27 & $\mathrm{~F}$ & Sí (2009) & 21 & 61 & $\begin{array}{l}\text { Síndrome de } \\
\text { impregnación, } \\
\text { fiebre, disfagia }\end{array}$ & $\begin{array}{l}\text { Pancitopenia, } \\
\text { elevación } \\
\text { de LDH y } \\
\text { ferritina }\end{array}$ & Hemocultivos & No & Sí & No & No \\
\hline 2 & 20 & $\mathrm{~F}$ & $\begin{array}{c}\text { Sí } \\
\text { (transmisión } \\
\text { vertical) }\end{array}$ & 15 & 31 & $\begin{array}{c}\text { Síndrome de } \\
\text { impregnación, } \\
\text { fiebre, úlcera } \\
\text { indolora en el } \\
\text { paladar }\end{array}$ & $\begin{array}{l}\text { Bicitopenia, } \\
\text { elevación } \\
\text { de enzimas } \\
\text { hepáticas y } \\
\text { LDH }\end{array}$ & $\begin{array}{l}\text { Escarificación } \\
\text { de mucosa } \\
\text { Hemocultivos }\end{array}$ & No & Sí & No & No \\
\hline 3 & 45 & M & Sí (2005) & 10 & 30 & $\begin{array}{c}\text { Síndrome de im- } \\
\text { pregnación, fiebre, } \\
\text { tos con expectora- } \\
\text { ción mucosa, lesión } \\
\text { ulcerada en el surco } \\
\text { nasogeniano }\end{array}$ & Pancitopenia & $\begin{array}{l}\text { Escarificación } \\
\text { cutánea } \\
\text { Hemocultivos }\end{array}$ & No & No & No & No \\
\hline 4 & 30 & M & No & 47 & 61 & $\begin{array}{c}\text { Síndrome de im- } \\
\text { pregnación, fiebre, } \\
\text { disnea, sudoración } \\
\text { nocturna, tos pro- } \\
\text { ductiva }\end{array}$ & $\begin{array}{l}\text { Bicitopenia y } \\
\text { elevación de } \\
\text { FAL }\end{array}$ & LBA & No & Sí & No & No \\
\hline 5 & 33 & M & Sí (2011) & 21 & 61 & $\begin{array}{c}\text { Síndrome de im- } \\
\text { pregnación, fiebre, } \\
\text { tos, lesiones papu- } \\
\text { losas y ampollares } \\
\text { en la piel asociado a } \\
\text { úlceras necróticas }\end{array}$ & Bicitopenia & $\begin{array}{l}\text { Hemocultivos } \\
\text { Biopsia } \\
\text { cutánea }\end{array}$ & No & Sí & No & No \\
\hline
\end{tabular}




\begin{tabular}{|c|c|c|c|c|c|c|c|c|c|c|c|c|}
\hline 6 & 51 & $\mathrm{~F}$ & Sí (1993) & 2 & 31 & $\begin{array}{l}\text { Síndrome de } \\
\text { impregnación, } \\
\text { fiebre, tos } \\
\text { productiva } \\
\text { hemoptoica, } \\
\text { disfagia }\end{array}$ & Anemia & Hemocultivos & No & Sí & No & No \\
\hline 7 & 42 & M & Sí (1995) & 120 & 31 & $\begin{array}{l}\text { Fiebre, tos } \\
\text { productiva, lesión } \\
\text { en el paladar }\end{array}$ & $\begin{array}{l}\text { Pancitopenia, } \\
\text { elevación } \\
\text { de enzimas } \\
\text { hepáticas y } \\
\text { FAL }\end{array}$ & $\begin{array}{l}\text { Hemocultivos } \\
\text { LBA } \\
\text { Escarificación } \\
\text { mucosa }\end{array}$ & MAl & Sí & No & No \\
\hline 8 & 37 & $M$ & Sí (1998) & $S / D$ & 59 & \begin{tabular}{|} 
Fiebre, tos \\
productiva \\
y pápulas \\
diseminadas en \\
tronco, cara y \\
extremidades, \\
eritema doloroso en \\
el tronco
\end{tabular} & Anemia & $\begin{array}{l}\text { Escarificación } \\
\text { cutánea } \\
\text { biopsia } \\
\text { cutánea }\end{array}$ & No & Sí & $\begin{array}{c}\text { Sí } \\
\text { (Irregular) }\end{array}$ & $S / D$ \\
\hline 9 & 45 & $M$ & Sí (1989) & 10 & 61 & $\begin{array}{c}\text { Síndrome de } \\
\text { impregnación, } \\
\text { fiebre, sudoración } \\
\text { nocturna, cefalea, } \\
\text { odinofagia, } \\
\text { lesiones costrosas } \\
\text { diseminadas }\end{array}$ & Bicitopenia & $\begin{array}{l}\text { Escarificación } \\
\text { cutánea }\end{array}$ & No & No & No & No \\
\hline 10 & 56 & M & Sí (1998) & $S / D$ & 153 & Disfonía & $\begin{array}{l}\text { Anemia, } \\
\text { elevación de } \\
\text { FAL }\end{array}$ & $\begin{array}{l}\text { Biopsia } \\
\text { laríngea }\end{array}$ & No & Sí & $\mid \begin{array}{c}\text { Sí } \\
\text { (Irregular) }\end{array}$ & $S / D$ \\
\hline 11 & 55 & $M$ & Sí (2001) & 24 & 61 & \begin{tabular}{|c|} 
Síndrome de \\
impregnación, \\
tos productiva, \\
odinofagia, dolor \\
abdominal, lesiones \\
moluscoides \\
en el tronco y \\
extremidades, lesión \\
ulcerada en el \\
paladar
\end{tabular} & $\begin{array}{c}\text { Pancitopenia } \\
\text { y elevación } \\
\text { de FAL }\end{array}$ & $\begin{array}{l}\text { Escarificación } \\
\text { de mucosa } \\
\text { Escarificación } \\
\text { cutánea } \\
\text { Hemocultivos } \\
\text { Esputo }\end{array}$ & No & No & $\begin{array}{c}\text { Sí } \\
\text { (Irregular) }\end{array}$ & No \\
\hline 12 & 54 & $M$ & No & 40 & 122 & $\begin{array}{c}\text { Síndrome de } \\
\text { impregnación, } \\
\text { disfagia a sólidos y } \\
\text { líquidos }\end{array}$ & Bicitopenia & $\begin{array}{l}\text { Biopsia } \\
\text { faríngea }\end{array}$ & No & Sí & No & No \\
\hline 13 & 50 & $M$ & No & 12 & 214 & $\begin{array}{c}\text { Síndrome de } \\
\text { impregnación, } \\
\text { odinofagia, disfagia, } \\
\text { lesión ulcerada en el } \\
\text { paladar }\end{array}$ & Bicitopenia & $\begin{array}{l}\text { Escarificación } \\
\text { cutánea } \\
\text { Escarificación } \\
\text { de mucosa } \\
\text { Hemocultivos } \\
\text { Exudado de } \\
\text { fauces }\end{array}$ & No & Sí & No & No \\
\hline 14 & 62 & $\mathrm{~F}$ & No & 6 & 30 & \begin{tabular}{|c|} 
Síndrome de \\
impregnación, \\
fiebre, tos \\
productiva, lesiones \\
en la mano \\
\end{tabular} & $\begin{array}{l}\text { Pancitopenia } \\
\text { y elevación } \\
\text { de enzimas } \\
\text { hepáticas, } \\
\text { FAL y ferritina }\end{array}$ & $\begin{array}{l}\text { Escarificación } \\
\text { cutánea } \\
\text { Hemocultivos }\end{array}$ & No & Sí & No & No \\
\hline 15 & 39 & $M$ & Sí (1999) & 12 & 31 & $\begin{array}{l}\text { Fiebre, lesiones } \\
\text { costrosas en la } \\
\text { cara y el tronco, } \\
\text { adenomegalias } \\
\text { cervicales, diarrea } \\
\text { no disentérica, } \\
\text { poliartragias }\end{array}$ & $\begin{array}{l}\text { Bicitopenia } \\
\text { y elevación } \\
\text { de enzimas } \\
\text { hepáticas }\end{array}$ & $\begin{array}{l}\text { Escarificación } \\
\text { cutánea }\end{array}$ & No & Sí & $\begin{array}{c}\text { Sí } \\
\text { (Irregular) }\end{array}$ & No \\
\hline 16 & 34 & M & Sí (2008) & 27 & 21 & $\begin{array}{c}\text { Fiebre, diarrea, tos } \\
\text { productiva, lesiones } \\
\text { papulosas en el } \\
\text { cuello, adenopatías }\end{array}$ & $\begin{array}{l}\text { Pancitopenia } \\
\text { y elevación } \\
\text { de FAL }\end{array}$ & $\begin{array}{c}\text { Biopsia } \\
\text { ganglionar } \\
\text { LBA }\end{array}$ & No & No & No & No \\
\hline
\end{tabular}




\begin{tabular}{|c|c|c|c|c|c|c|c|c|c|c|c|c|}
\hline 17 & 41 & $F$ & No & 61 & 31 & $\begin{array}{c}\text { Fiebre, cefalea, tos } \\
\text { no productiva }\end{array}$ & $\begin{array}{l}\text { Pancitopenia, } \\
\text { elevación } \\
\text { de enzimas } \\
\text { hepáticas, } \\
\text { FAL y ferritina }\end{array}$ & Hemocultivos & No & $\mathrm{SI}$ & No & No \\
\hline 18 & 58 & M & No & 21 & 61 & $\begin{array}{l}\text { Síndrome de } \\
\text { impregnación, tos } \\
\text { no productiva, } \\
\text { lesiones costro } \\
\text { eritematosas en } \\
\text { el rostro, cuello } \\
\text { y miembros } \\
\text { superiores }\end{array}$ & $\begin{array}{c}\text { Anemia, } \\
\text { elevación de } \\
\text { FAL y ferritina }\end{array}$ & $\begin{array}{l}\text { Escarificación } \\
\text { cutánea } \\
\text { Esputo }\end{array}$ & No & Sí & No & No \\
\hline 19 & 33 & M & No & 10 & 31 & $\begin{array}{l}\text { Síndrome de } \\
\text { impregnación, } \\
\text { fiebre, dolor } \\
\text { abdominal, tos } \\
\text { crónica }\end{array}$ & $\begin{array}{l}\text { Bicitopenia, } \\
\text { elevación } \\
\text { de enzimas } \\
\text { hepáticas, } \\
\text { FAL y LDH }\end{array}$ & $\begin{array}{c}\text { LBA } \\
\text { Hemocultivos } \\
\text { Biopsia de } \\
\text { intestino }\end{array}$ & No & Sí & No & No \\
\hline 20 & 40 & $\mathrm{~F}$ & Sí (1998) & 37 & 61 & \begin{tabular}{|c|} 
Fiebre, dolor nasal, \\
lesiones tipo eritema \\
polimorfo en el \\
dorso y palmas de \\
manos, lesiones \\
moluscoides en \\
el antebrazo, \\
tumoración en \\
paladar, perforación \\
del tabique nasal
\end{tabular} & $\begin{array}{l}\text { Anemia, } \\
\text { elevación } \\
\text { de enzimas } \\
\text { hepáticas }\end{array}$ & $\begin{array}{l}\text { Escarificación } \\
\text { de mucosa } \\
\text { Escarificación } \\
\text { cutánea }\end{array}$ & No & Sí & No & $\mathrm{N} / \mathrm{C}$ \\
\hline 21 & 37 & $F$ & Sí (2010) & 6 & 121 & \begin{tabular}{|c|} 
Síndrome de \\
impregnación, \\
fiebre, tos no \\
productiva, \\
disnea, pápulas y \\
lesiones costrosas \\
en los miembros \\
superiores e \\
inferiores
\end{tabular} & $\begin{array}{l}\text { Bicitopenia y } \\
\text { elevación de } \\
\text { LDH }\end{array}$ & $\begin{array}{l}\text { Escarificación } \\
\text { cutánea } \\
\text { Biopsia } \\
\text { cutánea } \\
\text { Hemocultivos }\end{array}$ & No & Sí & No & No \\
\hline 22 & 35 & $F$ & No & 24 & 28 & $\begin{array}{c}\text { Úlcera amigdalina, } \\
\text { adenomegalias } \\
\text { cervicales, } \\
\text { odinofagia }\end{array}$ & Anemia & $\begin{array}{l}\text { Biopsia de } \\
\text { amígdala }\end{array}$ & No & Sí & No & No \\
\hline 23 & 43 & $F$ & Sí (2009) & 50 & 61 & \begin{tabular}{|c|} 
Síndrome de \\
impregnación, \\
fiebre, cefalea, \\
tos no productiva, \\
dolor abdominal \\
con hepato- \\
esplenomegalia \\
\end{tabular} & $\begin{array}{l}\text { Pancitopenia, } \\
\text { elevación } \\
\text { de enzimas } \\
\text { hepáticas y } \\
\text { LDH }\end{array}$ & $\begin{array}{l}\text { Hemocultivos } \\
\text { LBA }\end{array}$ & No & Sí & $\begin{array}{c}\text { Sí } \\
\text { (irregular) }\end{array}$ & Sí \\
\hline 24 & 41 & M & No & 14 & 14 & $\begin{array}{l}\text { Síndrome de } \\
\text { impregnación, } \\
\text { sudoración } \\
\text { nocturna, tos }\end{array}$ & $\begin{array}{l}\text { Bicitopenia, } \\
\text { elevación } \\
\text { de enzimas } \\
\text { hepáticas, } \\
\text { ferritina y } \\
\text { LDH }\end{array}$ & LBA & No & Sí & No & Sí \\
\hline 25 & 64 & $M$ & No & 65 & 122 & $\begin{array}{l}\text { Síndrome de } \\
\text { impregnación, } \\
\text { fiebre, tos }\end{array}$ & $\begin{array}{l}\text { Bicitopenia, } \\
\text { elevación de } \\
\text { ferritina }\end{array}$ & LBA & $\begin{array}{l}\text { Candidiasis } \\
\text { esofágica }\end{array}$ & Sí & No & Sí \\
\hline 26 & 29 & $M$ & No & 4 & 92 & $\begin{array}{c}\text { Síndrome de } \\
\text { impregnación, } \\
\text { diarrea, sudoración } \\
\text { nocturna, tos } \\
\text { productiva }\end{array}$ & $\begin{array}{l}\text { Pancitopenia, } \\
\text { elevación } \\
\text { de enzimas } \\
\text { hepáticas y } \\
\text { FAL }\end{array}$ & $\begin{array}{l}\text { Hemocultivos } \\
\text { LBA }\end{array}$ & No & Sí & No & No \\
\hline 27 & 21 & $\mathrm{~F}$ & Sí (2011) & 5 & 30 & $\begin{array}{c}\text { Lesiones costrosas } \\
\text { en la cara y el } \\
\text { tronco }\end{array}$ & $\begin{array}{l}\text { Bicitopenia, } \\
\text { elevación } \\
\text { de enzimas } \\
\text { hepáticas y } \\
\text { LDH }\end{array}$ & $\begin{array}{l}\text { Hemocultivos } \\
\text { Escarificación } \\
\text { cutánea }\end{array}$ & No & Sí & No & Sí \\
\hline
\end{tabular}




\begin{tabular}{|c|c|c|c|c|c|c|c|c|c|c|c|c|}
\hline 28 & 37 & M & Sí (1988) & 28 & 59 & $\begin{array}{c}\text { Síndrome de } \\
\text { impregnación, } \\
\text { fiebre, tos produc- } \\
\text { tiva, vómitos, dolor } \\
\text { abdominal, placas } \\
\text { eritemato violáceas } \\
\text { diseminadas }\end{array}$ & $\begin{array}{l}\text { Anemia, } \\
\text { elevación de } \\
\text { LDH }\end{array}$ & LBA & \begin{tabular}{|c|} 
Sarcoma de \\
Kaposi cutáneo \\
Toxoplasmosis \\
cerebral \\
Candidiasis \\
esofágica
\end{tabular} & Sí & No & No \\
\hline 29 & 42 & $M$ & No & 3 & 14 & \begin{tabular}{|c|} 
Debilidad facio- \\
braquio-crural \\
izquierda, fiebre, \\
pápulas con \\
umbilicación central \\
y otras con centro \\
necrótico
\end{tabular} & $\begin{array}{l}\text { Pancitopenia } \\
\text { y elevación } \\
\text { de enzimas } \\
\text { hepáticas, } \\
\text { LDH y } \\
\text { ferritina }\end{array}$ & $\begin{array}{l}\text { Hemocultivos } \\
\text { Escarificación } \\
\text { cutánea } \\
\text { Biopsia } \\
\text { cutánea }\end{array}$ & No & Sí & No & Sí \\
\hline 30 & 48 & $\mathrm{~F}$ & No & 3 & 92 & $\begin{array}{c}\text { Síndrome de } \\
\text { impregnación, } \\
\text { fiebre, dolor } \\
\text { abdominal, vómitos }\end{array}$ & $\begin{array}{l}\text { Pancitopenia, } \\
\text { elevación } \\
\text { de enzimas } \\
\text { hepáticas y } \\
\text { LDH }\end{array}$ & Hemocultivos & No & Sí & No & No \\
\hline 31 & 43 & $M$ & Sí (2007) & 11 & 62 & $\begin{array}{c}\text { Síndrome de } \\
\text { impregnación, tos } \\
\text { productiva, úlcera } \\
\text { en la mucosa yugal } \\
\text { y el paladar }\end{array}$ & $\begin{array}{l}\operatorname{Sin} \\
\text { alteraciones }\end{array}$ & $\begin{array}{c}\text { Escarificación } \\
\text { de mucosa }\end{array}$ & No & Sí & No & No \\
\hline 32 & 40 & $M$ & No & 5 & 21 & \begin{tabular}{|c|} 
Síndrome de \\
impregnación, \\
fiebre, tos no \\
productiva, \\
sudoración \\
nocturna, lesiones \\
cutáneas eritemato- \\
descamativas \\
diseminadas
\end{tabular} & $\begin{array}{l}\text { Bicitopenia, } \\
\text { elevación } \\
\text { de enzimas } \\
\text { hepáticas, } \\
\text { LDH y } \\
\text { ferritina }\end{array}$ & $\begin{array}{c}\text { Escarificación } \\
\text { cutánea }\end{array}$ & $\begin{array}{c}\text { Criptococosis } \\
\text { diseminada }\end{array}$ & Sí & No & No \\
\hline 33 & 42 & $M$ & Sí (2009) & 19 & 90 & $\begin{array}{l}\text { Síndrome de } \\
\text { impregnación, tos } \\
\text { no productiva, } \\
\text { diarrea, lesiones } \\
\text { papulo-costrosas } \\
\text { diseminadas en la } \\
\text { piel y el paladar }\end{array}$ & $\begin{array}{l}\text { Anemia, } \\
\text { elevación } \\
\text { de enzimas } \\
\text { hepáticas y } \\
\text { LDH }\end{array}$ & $\begin{array}{c}\text { Esputo } \\
\text { Hemocultivos } \\
\text { Escarificación } \\
\text { cutánea } \\
\text { Escarificación } \\
\text { de mucosa }\end{array}$ & No & Sí & $\begin{array}{c}\text { Sí } \\
\text { (Irregular) }\end{array}$ & No \\
\hline 34 & 46 & $\mathrm{~F}$ & Sí (2002) & 29 & & Úlcera en el paladar & $\begin{array}{l}\text { Pancitopenia, } \\
\text { elevación } \\
\text { de enzimas } \\
\text { hepáticas y } \\
\text { FAL }\end{array}$ & $\begin{array}{c}\text { Escarificación } \\
\text { de mucosa }\end{array}$ & No & No & No & No \\
\hline 35 & 44 & $M$ & No & 7 & 212 & \begin{tabular}{|c|} 
Síndrome de im- \\
pregnación, fiebre, \\
tos productiva, \\
lesión ulcerada \\
de bordes netos y \\
fondo de fibrina \\
en el paladar duro, \\
adenomegalias \\
axilares e inguinales \\
dolorosas
\end{tabular} & $\begin{array}{l}\text { Bicitopenia y } \\
\text { elevación de } \\
\text { LDH }\end{array}$ & $\begin{array}{c}\text { Escarificación } \\
\text { de mucosa }\end{array}$ & $\begin{array}{c}\text { TBC } \\
\text { Salmonelosis } \\
\text { sistémica no } \\
\text { tífica }\end{array}$ & Sí & No & No \\
\hline 36 & 53 & $M$ & Sí (2006) & 61 & & $\begin{array}{l}\text { Adenopatías } \\
\text { cervicales }\end{array}$ & $\begin{array}{l}\text { Bicitopenia y } \\
\text { elevación de } \\
\text { ferritina }\end{array}$ & $\begin{array}{l}\text { Biopsia } \\
\text { ganglionar }\end{array}$ & No & NO & $\begin{array}{c}\text { Sí } \\
\text { (irregular) }\end{array}$ & No \\
\hline 37 & 33 & M & No & 13 & 31 & $\begin{array}{c}\text { Síndrome de } \\
\text { impregnación, } \\
\text { fiebre, tos no } \\
\text { productiva, lesiones } \\
\text { equimóticas y } \\
\text { eritematosas en el } \\
\text { tronco }\end{array}$ & $\begin{array}{l}\text { Bicitopenia y } \\
\text { elevación de } \\
\text { ferritina }\end{array}$ & $\begin{array}{l}\text { Hemocultivos } \\
\text { Biopsia } \\
\text { bronquial } \\
\text { LBA }\end{array}$ & No & Sí & No & No \\
\hline
\end{tabular}




\section{Referencias bibliográficas}

1.- Kauffman C A. Histoplasmosis. En: Dismukes WE, Pappas P G, Sobel J D. (ed.), Clinical Mycology. New York, NY: Oxford University Press 2003; 285-98.

2.- Iriart X, Blanchetb D, Menardf S, Lavergnea R, Chauvina P, Adenisd A, et al. A complementary tool for management of disseminated Histoplasma capsulatum var. capsulatum infections in AIDS patients. Intern J Med Microbiol 2014; 304: 1062-5. http://www.hal. inserm.fr/inserm-01065096

3.- Frola J, Bermejo V, Spadaccini L, Guelfand L, Pérez H. Compilación estadística. Impacto de la histoplasmosis diseminada en pacientes HIV positivos. Actualizaciones en SIDA e Infectología - Buenos Aires. 2013; 80: 37-41. https:/www.huesped.org.ar/wp-content/ uploads/2014/11/ASEI-80-37-41.pdf

4.- Wheat L J, Freifeld A G, Kleiman M B, Baddley J W, McKinsey D S, Loyd J E, et al. Clinical practice guidelines for the management of patients with histoplasmosis: 2007 update by the Infectious Diseases Society of America. Clin Infect Dis. 2007; 45: 807-25. DOI: $10.1086 / 521259$

5.- Arenas R. Micología Médica ilustrada. 4ta ed. McGraw-Hill. 2011; Sección IV: 193-201.

6.- Bialek R, Feucht A, Aepinus C, Just-Nübling G, Robertson V, Knobloch J, et al. Evaluation of two nested PCR Assays for Detection of Histoplasma capsulatum DNA in human tissue. J Clin Microbiol 2002; 40 (5): 1644-1647; DOI: 10.1128/JCM.40.5.1644-1647.2002.

7.- Negroni R, Arechavala A I, Maiolo E I. Histoplasmosis clásica en inmunocomprometidos. Med Cutan IberLat Am
2010; 38: 59-69. http://www.medigraphic.com/ pdfs/cutanea/mc-2010/mc102b.pdf

8.- Kauffman C A. Histoplasmosis: a clinical and laboratory update. Clin Microbiol Rev.2007; 20: 115-32. DOI: 10.1128/CMR.00027-06.

9.- Vail G M, Mocherlas S, Wheat L J, Goldberg J, Camp A, Brizendine E, et al. Cellular immune response in HIV-infected patients with histoplasmosis. J Acquir Immune Defic Syndr 2002; 29: 49-53. PMID: 1178258.

10.- Negroni R. Histoplasmosis en América Latina. Biomédica.2011; 31: 304. DOI: https://doi. org/10.7705/biomedica.v31i3.597.

11.- Wheat L J, Connolly-Stringfield P A, Baker R L, Curfman M F, Eads M E, Israel K S, et al. Disseminated histoplasmosis in the acquired immune deficiency syndrome: clinical findings, diagnosis and treatment, and review of the literature. Medicine (Baltimore) 1990; 69: 24460. PMID: 2233233.

12.- Guelfand L, Cahn P. Histoplasmosis. En: Ausina Ruiz V, Moreno Guillén S, editores. Tratado SEIMC de Enfermedades Infecciosas y Microbiología Clínica. Madrid: Editorial Médica Panamericana; 2006; 659-64.

13.- Negroni R, Robles A M, Arechavala A. Histoplasmosis progresiva. Estudio en un lapso de 10 años. Rev Argent Micología 1994; 17: 14-21.

14.- Wheat J. Endemic mycoses in AIDS: a clinical review. Clin Microbiol Rev 1995; 8: 146-59. PMID: 7704892.

15.- Goldani L Z, Aquino V R, Lunardi L W, Cunha V S, Santos R P. Two specific strains of Histoplasma capsulatum causing mucocutaneous manifestations of histoplasmosis: preliminary analysis of a frequent manifestation of histoplasmosis in southern Brazil. Mycopathologia 2009; 167 : 181-6. doi: 10.1007/s11046-008-9171-7.

16.- Baddley J W, Bartlett J G, Mitty J. Diagnosis and treatment of histoplasmosis in HIVinfected patients. uptodate.com. 2015. https:// www.uptodate.com/contents/diagnosis-andtreatment-of-histoplasmosis-in-HIV-infectedpatients

17.- López Daneri A, Arechavala A, Iovannitti C, Mujica M. Histoplasmosis diseminada en pacientes HIV/SIDA. Buenos Aires, 20092014. Revista Medicina 2016; 76: 332-7. https://medicinabuenosaires.com/revistas/ vol76-16/n6/332-337-Med76-5-6541-Daneri-A. pdf.

18.- Sperb Antonello V, Ferrazza Zaltron V, Vial M, Mattos de Oliveira F, Severo L C. Oropharyngeal histoplasmosis: report of eleven cases and review of the literature. Rev Soc Bras Med Trop 2011; 44 (1): 26-9. http://dx.doi.org/10.1590/S003786822011000100007.

19.- Assi M, McKinsey D S, Driks M R, O'Connor M C, Bonacini M, Graham B, et al. Gastrointestinal histoplasmosis in the acquired immunodeficiency syndrome: report of 18 cases and literature review. Diagn Microbiol Infect Dis 2006; 55: 195-201. DOI: 10.1016/j. diagmicrobio.2006.01.015.

20.- Rickerts V, Bialek R, Tintelnot K, Jacobi V, Just-Nübling G. Rapid PCR-based diagnosis of disseminated histoplasmosis in an AIDS patient. Eur J Clin Microbiol Infect Dis 2002; 21: 821-3. DOI: 10.1007/s10096-002-0833-y.

21.- Martagon-Villamil J, Shrestha N, Sholtis M, et al. Identification of Histoplasma capsulatum from culture extracts by real-time PCR. J Clin Microbiol 2003; 41: 1295-8. DOI: 10.1128/ JCM.41.3.1295-1298.2003. 